\title{
The beginning of the movement of bottom sediments in an unsteady flow
}

\author{
Sobir Eshev ${ }^{1 *}$, Isroil Gaimnazarov ${ }^{1}$, Shakhboz Latipov $^{1}$, Nurbek Mamatov ${ }^{1}$, Feruz Sobirov $^{2}$ \\ and Iroda Rayimova ${ }^{3}$ \\ ${ }^{1}$ Karshi engineering-economics institute, Kashkadarya, Uzbekistan \\ ${ }^{2}$ Bukhara branch of the Tashkent Institute of Irrigation and Agricultural Mechanization Engineers, \\ Bukhara, Uzbekistan \\ ${ }^{3}$ Tashkent Institute of Irrigation and Agricultural Mechanization Engineers, Tashkent, Uzbekistan
}

\begin{abstract}
This article discusses the problems of determining the friction parameter and non-eroding conditions in a wave flow are considered from the standpoint of an approach using a critical dynamic speed. In the first stage of research, the question of the formation of an unsteady turbulent boundary layer is substantiated. Because of the research, dependences were obtained for the most important value from the point of view of sediment transport - the friction parameter. Based on the data of these measurements, a plot of dependence was built, which differs from the previously obtained analytical relationships. For the convenience of practical use of the obtained empirical connection approximated.

The second stage of research is the development of a method for calculating the critical tangential stresses corresponding to the beginning of the movement of bottom sediments. Based on the Shilds method, a curve similar to the Shilds curve for wave flow conditions was constructed, which was approximated for the convenience of practical use.
\end{abstract}

\section{Introduction}

Currently, there is an extensive literature on the study of the onset of erosion with uniform movement of water, and due to the complexity of the nature of unsteady currents, a dependence has not yet been proposed that reflects the process of the beginning of erosion of channels, in conditions of wave flows [2,4,6,7,10, 12,13,14,15,16,].

When studying and solving problems related to forecasting sediment transport in the presence of various kinds of wave (non-stationary) movements, the question of the formation of a nonstationary turbulent boundary layer takes the leading place. Therefore, it is no coincidence, which the study of erosion processes caused by wave flows.In most cases, begins with the study of the structural features of the boundary layer, which in natural conditions is predominantly turbulent. Now, thanks to the fundamental research of a

\footnotetext{
* Corresponding author: eshevsobir@gmail.com
} 
number of authors $[3,8,9,18,19,20]$, in the theory of the boundary layer to achieve sufficiently great success. However, in view of the great mathematical difficulties in describing the process of formation of a boundary layer under conditions of an oscillatory (oscillating) nature of motion.At the present stage, there are still entertaining gaps, and first of all, in the field of reliable quantitative assessment of the parameters of non-stationary layers, which largely determines the correctness making design decisions in hydraulic engineering.

The existing mathematical models of the boundary layer in most cases are based on equations obtained after a number of simplifications of the general system of Navier-Stokes equations.

One of the first models of an oscillating boundary layer is the solution [17]. The author used the concept of turbulent viscosity to create a three-layer model; in a thin inner layer, the turbulent viscosity was assumed to be constant, in the intermediate layer it was assumed to be linearly dependent on the distance to the bottom, and finally, at some distance from the bottom.It was again assumeda constant value (outer layer). Using the equation of conservation of the moments of motion in [17], a very complex numerical-analytical solution was obtained. Later, Brevik greatly simplified the solution [17] by excluding the inner layer from the analysis. Both authors compared their theoretical results with the experimental data of Johnson [9] and obtained a fairly good agreement. However, the following can be noted as the disadvantages of these theories: 1) they do not take into account the non-stationary of the turbulent viscosity coefficient; 2) the thickness of the boundary layer was taken as a time independent value; and 3) the change in the tangential stress was assumed to be sinusoidal.

Some of these shortcomings were later eliminated in the models of Johnson and Carlsen [21 - 29]. Using also the equation of conservation of momentum over the thickness of the boundary layer and assuming that the velocity distribution in the boundary layer obeys a logarithmic law, the authors obtained an expression for the friction parameter for the case of fully expressed roughness. However, since the equations were integrated over the wave period, detailed (within the wave cycle) changes in the tangential stresses and phase displacement between the maxima of the orbital velocity and tangential stresses were not described. In addition, changes in the boundary layer with time were considered negligible and the integration constant was determined from experimental data.

\section{Method}

Analyzing a far from complete list of existing models of unsteady turbulent boundary layer, I would like to mention the last of Fredsoe's works [21], in which the author carries out a rather rigorous analytical analysis and obtained results that are in fairly good agreement with experimental data.

The mathematical subtleties of the existing models of the boundary layer have not gone into the following: in each theoretical development, an attempt was made (more or less successful) to obtain a dependence for the most important value from the point of view of sediment transport $-f=2 u_{*_{m}}^{2} / u_{m}^{2}$. The friction parameter (here $u_{*_{m}}$ is the maximum value of the dynamic velocity in the wave flow, $u_{m}$ - the maximum value of the orbital velocity at the outer edge of the turbulent boundary layer). At the same time, in a number of cases, researchers managed to obtain dependences that are in good agreement with the experimental data (Fig. 1). However, this correspondence, in our opinion, is insufficient for the development of reliable methods for forecasting sediment transport during waves. Therefore, the purpose of our work was to generalize the existing laboratory and field data to obtain a sufficiently reliable empirical dependence for calculating the friction parameter, 
including the characteristic $u_{*_{m}}$ that is most important for solving the problem of sediment transport in wave flows.

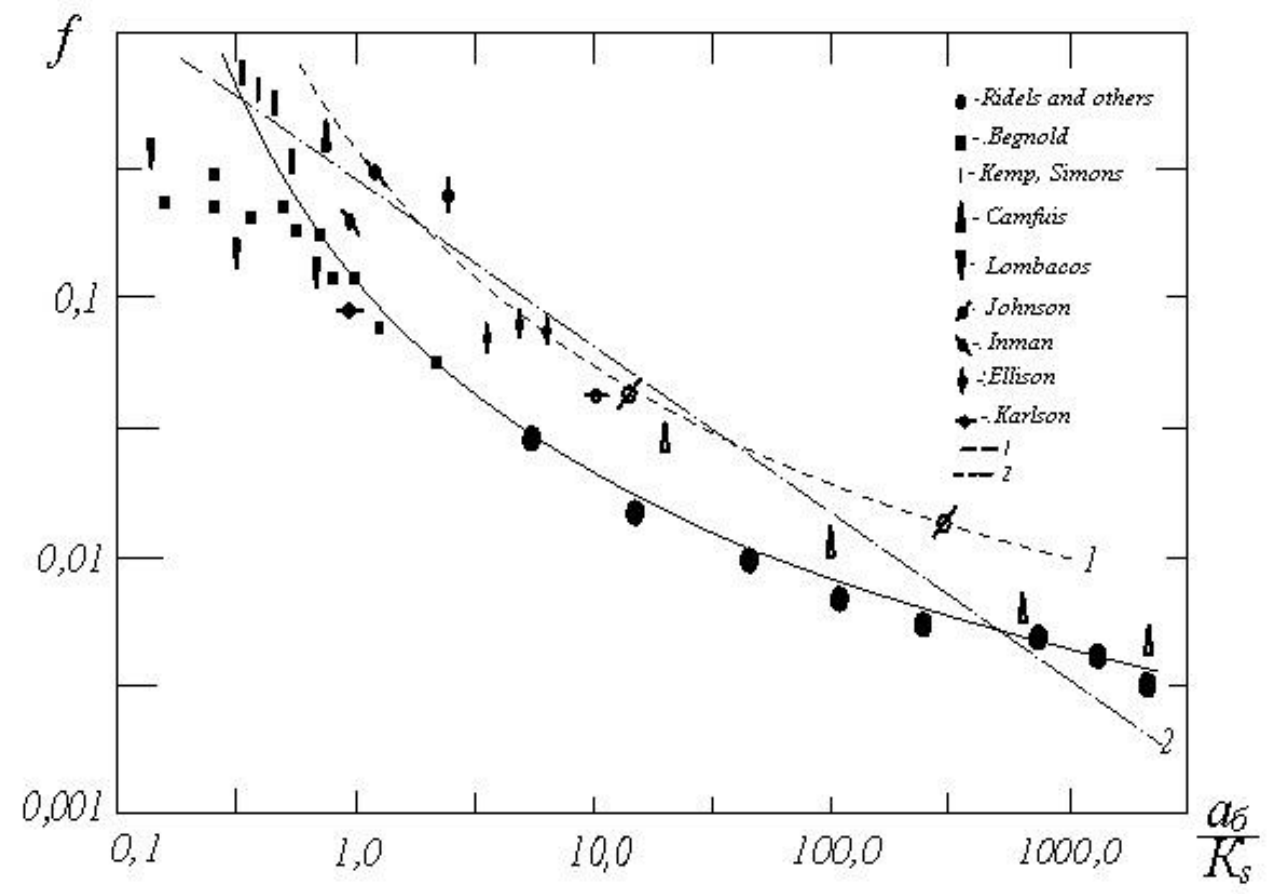

Fig. 1. Communication graph $f=f c t\left(a_{\sigma} / K_{s}\right) .1$ - link], 2 - link [9].

\section{Results and Discussion}

As a result of the analysis of modern literature [3]), the data of 51 measurements of the change in the parameter $f$ and $a_{\delta} / K_{S}$ (where $\left.a_{\delta}=u_{m} / w\right)$ were obtained. Based on the data of these measurements, the dependence $f=f_{c t}\left(a_{\delta} / K_{s}\right)$ is plotted, shown in Fig. 4.9, which, in our opinion, differs favorably from the previously obtained analytical relationships. For the convenience of practical use of the obtained empirical connection, it was approximated with an accuracy of $2 \%$ by a series of dependences in the form:

$$
\left.\begin{array}{llrl}
\xi=0.05\left(\frac{\alpha}{\kappa}\right)^{-0,308} & \text { at } & 200<\frac{\alpha}{\kappa} \\
\xi & =0.105\left(\frac{\alpha}{\kappa}\right)^{-0,444} & \text { at } & 25<\frac{\alpha}{\kappa} \leq 200 \\
\xi=0.204\left(\frac{\alpha}{\kappa}\right)^{-0,650} & \text { at } & 2.5<\frac{\alpha}{\kappa} \leq 25 \\
\xi=0.279\left(\frac{\alpha}{\kappa}\right)^{-0,978} & \text { at } & 0.4<\frac{\alpha}{\kappa} \leq 2.5 \\
\xi=0.214\left(\frac{\alpha}{\kappa}\right)^{-1,270} & \text { at } & \frac{\alpha}{\kappa} \leq 0.4 .
\end{array}\right\}
$$


Dependences (1) can be used in calculations of sediment transport and erosion processes under wind waves.

When modeling the stability of channels to erosion, as we have already said, two approaches are currently used:

1) the method of non-eroding velocities, which makes it possible to obtain calculation formulas that represent a generalized hydraulic characteristic of the stability of the soil to erosion, and 2) the method of entrainment force (shear force or force friction), which acts on the channel bed in the direction of flow.

At this time, there are a large number of dependencies for determining non-eroding water flow rates for various soils, which are obtained either purely empirically, or on the basis of certain prerequisites for the limiting equilibrium of particles with the introduction of a number of additional parameters to take into account various factors affecting soil erosion $[1,2]$.

Another approach, based on the consideration of the limiting pulling force, uses the concept of the critical dynamic velocity $U_{* k p}$ corresponding to the onset of sediment movement. The foundations of this approach were first formulated by Shilds [11], who, using the method of dimensions, proposed two main dimensionless complexes that determine the conditions for the beginning of the movement of bottom sediments:

$$
\begin{aligned}
& \theta_{k p}=\frac{U_{* k p}^{2}}{(S-1) g d_{c p}} ; \\
& D_{*}=d_{c p}\left[\frac{g(S-1)}{v^{2}}\right]^{\frac{1}{3}},
\end{aligned}
$$

where $U_{{ }_{k p}}$-critical dynamic speed of the beginning of the movement of bottom sediments; $\mathrm{g}$ - acceleration of gravity; $d_{c p}$ - average diameter of bottom sediments; $\mathrm{S}$ is the relative density of the bottom soil; $v$ - coefficient of molecular kinematic viscosity.

Using a large array of actual data, the author of [11] obtained the dependence in the form

$$
\theta_{k p}=f c t D_{*},
$$

which later became known as the Schilds curve.

For the convenience of practical use of the Schilds curve, it is approximated by a series of dependences:

$$
\begin{aligned}
& \theta_{k p}=0.24\left(D_{*}\right)^{-1} \quad \text { at } \quad D_{*} \leq 4 \\
& \theta_{k p}=0.14\left(D_{*}\right)^{-0,66} \text { at } 4 \prec D_{*} \leq 10 \\
& \theta_{k p}=0.040\left(D_{*}\right)^{-0,10} \text { at } 10 \prec D_{*} \leq 20 \\
& \theta_{k p}=0.013\left(D_{*}\right)^{-0,29} \text { at } \quad 20 \prec D_{*} \leq 150 \\
& \theta_{k p}=0.055 \quad \text { at } \quad D_{*} \succ 150
\end{aligned}
$$

In contrast to the comprehensive study and the presence of a large variety of calculation formulas for the conditions for the beginning of the movement of bottom sediments in unidirectional flows, the critical conditions for wave movement are insufficiently studied. It also traces the study of non-eroding conditions in wave flows using the approaches described above: by methods of non-eroding velocities and from the standpoint of analyzing critical tangential stresses arising at the bottom of oscillating flows. 
In the first approach, based on the calculation of non-eroding velocities, the maximum orbital velocities at the bottom are selected as the latter under the conditions of a wave flow, which, in accordance with Stosk's linear theory, can be represented as:

$$
u_{m}=\frac{\pi \cdot h_{b}}{\tau \cdot \operatorname{shkh}}
$$

where $k=2 \pi / \lambda ; h_{b}, \lambda, \tau$ - respectively, the height, length and period of surface waves.

Here are the main calculated dependencies, which are based on the method of noneroding velocities in a wave flow:

Bagnold [21]:

$$
\frac{\omega^{1,4} u_{m}^{3,4}}{(S-1) d_{a v}^{0,325}}=21.5
$$

Manohar [22]:

$$
\frac{u_{m}}{\left[g(S-1) d_{a v}^{0.4}\left(v d_{a v}\right)^{0.2}\right]}=\left\{\begin{array}{l}
7.45(\text { start moving }) \\
8.20(\text { general movement })
\end{array}\right.
$$

Komar, Müller [21]:

$$
\frac{u_{m}^{2}}{g(S-1) d_{a v}}=\left\{\begin{array}{l}
0.21\left(\frac{2 \mathrm{Q} \delta}{\mathrm{d}_{a v}}\right)^{1 / 2}\left(d_{a v} \succ 0.05 \mathrm{~cm}\right) \\
0.46 \pi\left(\frac{2 Q \delta}{d_{a v}}\right)^{1 / 4}\left(d_{a v} \succ 0.05 \mathrm{~cm}\right)
\end{array}\right.
$$

where $a_{\delta}=u_{m} / \omega, \omega=2 \pi / \tau$.

Mass E.I. [5]:

$$
u_{m}=1.34 \sqrt{\frac{g}{\gamma}\left[\left(\gamma_{S}-\gamma\right) d_{c p}+2 C_{Y}^{H} K\right]}
$$

where $\gamma_{S}, \gamma$ is the specific gravity of sediment and water; $C_{Y}^{H}$ - fatigue tensile strength of non-cohesive soil, $C_{Y}^{H}=175 / 10^{-10} \mathrm{~d}_{\mathrm{cp}}\left(\mathrm{T} / \mathrm{m}^{2}\right)$; $\mathrm{K}$ is the uniformity coefficient characterizing the probability of deviation of the magnitude of the emerging adhesion forces from its average value $(K=0.5)$.

It should be noted that in most cases the given dependences are in satisfactory agreement only with the experimental data on the basis of which they were obtained.

Often, in the practice of solving problems of applied hydraulics, knowledge of the critical tangential stress is required, which corresponds to the beginning of the movement of bottom sediments with a wave of a given supply. In other words, it becomes necessary to consider the problem of determining non-blurring conditions in a wave flow from the standpoint of the second approach, which uses the critical dynamic velocity. The purpose of this work is to develop a method for calculating the critical tangential stresses corresponding to the beginning of the movement of bottom sediments. The results of laboratory studies were used as the initial data [5]. The analysis was based on the Schilds method, which involves the determination of the relationship 
where

$$
\theta_{k p}^{\prime}=f c t D
$$

$$
\theta_{k p}^{\prime}=\frac{u_{*_{m}}^{2}}{g d(S-1)}
$$

Here $\mathcal{U}_{* m}$ is the maximum value of the dynamic velocity in the wave flow, which is calculated using the empirical relationships obtained by the authors earlier [21]:

$$
\left.\begin{array}{rrrr}
u_{* b}=0.158 u_{b}\left(\frac{\alpha}{\kappa}\right)^{-0.154} & \text { at } & 200 \prec \frac{\alpha}{\kappa} \\
u_{* b}=0.229 u_{b}\left(\frac{\alpha}{\kappa}\right)^{-0.222} & \text { at } & 25 \prec \frac{\alpha}{\kappa} \leq 200 \\
u_{* b}=0.319 u_{b}\left(\frac{\alpha}{\kappa}\right)^{-0.325} & & \text { at } & 2,5 \prec \frac{\alpha}{\kappa} \leq 25 \\
u_{* b}=0.373 u_{b}\left(\frac{\alpha}{\kappa}\right)^{-0.489} & & \text { at } & 0,4 \prec \frac{\alpha}{\kappa} \leq 2.5 \\
u_{* b}=0.377 u_{b}\left(\frac{\alpha}{\kappa}\right)^{-0.635} & & \text { at } & \frac{\alpha}{\kappa} \leq 0.4
\end{array}\right\}
$$

$$
\text { where } \kappa=2,5 d_{c p} ; \alpha=u_{m} \tau / 2 \pi ; u_{m}=\frac{h_{b} \pi}{\tau \cdot \operatorname{sh} \frac{2 \pi h_{c p}}{\lambda}}
$$

As a result of the analysis, a curve (Fig. I) (similar to the Schilds curve) was obtained for the conditions of the wave flow.

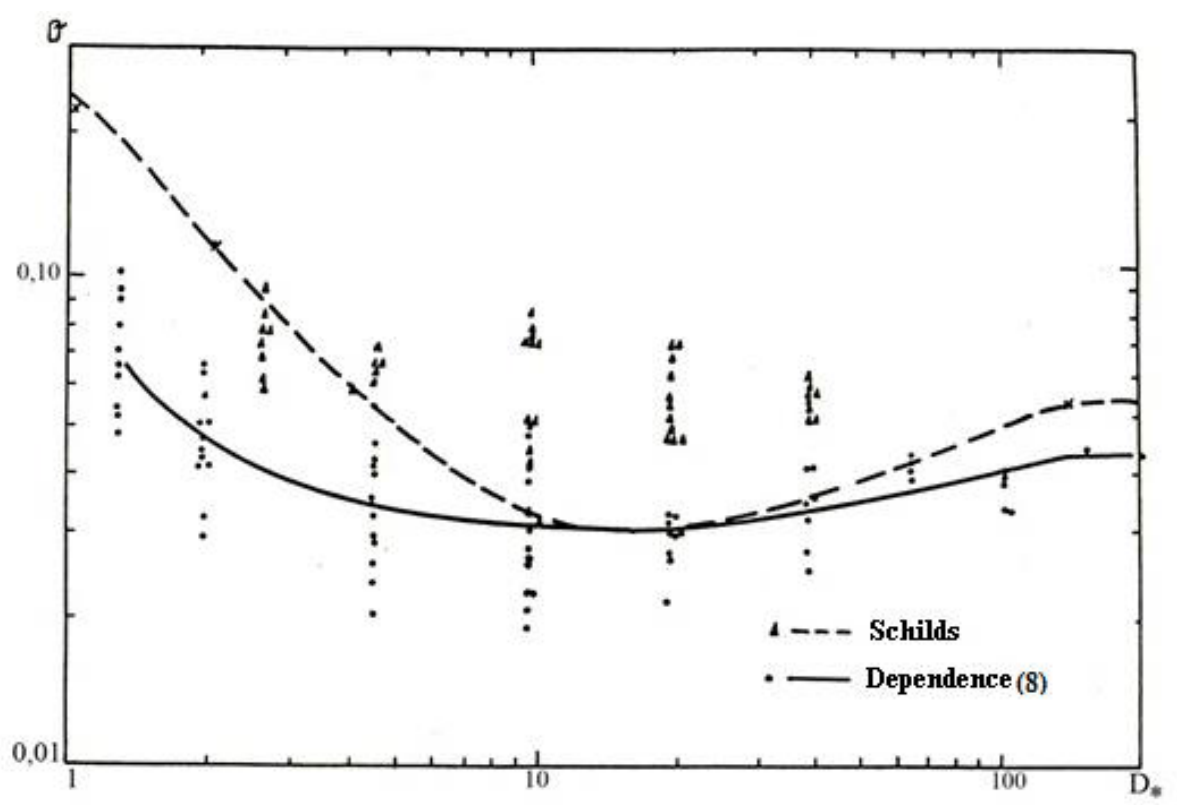

Fig. 2. Dependency graph $Q=f c t\left(D_{*}\right)$. 
For the convenience of practical use, the dependence graph was approximated in the form:

$$
\left.\begin{array}{rlrc}
\theta_{k p}^{\prime} & =0.08\left(D_{*}\right)^{-0.810} & \text { at } & D_{*} \leq 2 \\
\theta_{k p}^{\prime}=0.06\left(D_{*}\right)^{-0.402} & \text { at } & 2 \prec D_{*} \leq 4 \\
\theta_{k p}^{\prime}=0.041\left(D_{*}\right)^{-0.118} & \text { at } & 4 \prec D_{*} \leq 10 \\
\theta_{k p}^{\prime}=0.032\left(D_{*}\right)^{-0.017} & \text { at } & 10 \prec D_{*} \leq 20 \\
\theta_{k p}^{\prime}=0.018\left(D_{*}\right)^{0.174} & \text { at } & 20 \prec D_{*} \leq 150 \\
\theta_{k p}=0.0435 & \text { at } & D_{*} \succ 150
\end{array}\right\}
$$

(8)

Comparison obtained by the curve with the Schilds curve shows (Fig. 2) that, in the general case, in a wave flow, the beginning of the movement of bottom sediments occurs at lower tangential stresses than in a unidirectional flow.

\section{Conclusions}

In conclusion, the following conclusions can be drawn:

1. Dependences (1) can be used in calculating sediment transport and erosion processes under wind waves.

2. The proposed algorithm (6) - (8) can be recommended for calculating the critical conditions for the beginning of the movement of bottom sediments in wave flows, the knowledge of which is necessary when solving a wide range of problems of applied hydraulics.

\section{References}

1. Antsyferov S.M., Kantarzhi I.G. Bottom boundary condition for calculating the concentration of sediments suspended by waves and current // Oceanology. 2000. T. 40, No. 4, p- 606-.613.

2. Kantarzhi I. G. Shevchenko K. I. Determination of the coefficient of bottom friction under the waves in the flow. // Meteorology and Hydrology. 1990. No. 4. P-88-95.

3. Longuet - Higgins M.S. Surf zone mechanics. - Mechanics, 1974, No. 1, P-84 - 103.

4. A Yangiev, ,S.Eshev ,ShPanjiev. Calculation of sediment flow in channels taking into account passing and counter wind waves. CONMECHYDRO - 2020 IOP Conf. Series: Materials Science and Engineering. 883 (2020) 012036 . IOPPublishing .doi:10.1088/1757-899X/883/1/012036.

5. Mass E.I. Study of non-blurring wave flow velocities for non-cohesive soils. Author's abstract. diss. for a job. uch. step. Cand. tech. sciences. Tbilisi, 1968 .P- 27.

6. Mass E.I., Kantarzhi I.G. et al. Method for calculating wind waves in large channels. // Water resources, 1988, No. 1, P- 60-67.

7. Nikitin I.K. Turbulent channel flow and processes in the bottom area. Kiev, Ed. Academy of Sciences of the Ukrainian SSR, 1963 .P- 142.

8. Jonson J.D.G. Combination of waves and currents. - Rept. Dan. Cent Appl. Math and Mech., 1979, s. 15 , p. $161-203$ 
9. Jonsson J.O. Carisen N.A. Experimental and theoritikal investigations in an oscillatory turbulent boundary layer. J. Hydraul. Res., v. 14. No 1, 1976, 45 -

10. S.Eshev ,A.Khazratov, A Rakhimov, Sh. A. LatipovInfluence of wind waves on the flow in flowing reservoirs. IIUM Engineering Journal, Vol. 21, No. 2, 2020. P.125132.DOI: https://doi.org/10/31436/iiumej.v21i2.1329.

11. Schields A. Anwendungde der Ahnlichkeitsmechnic und deirTurbulenzforshungaur die diegeschiebebeweggung. Mitteilungen der Preesseveesuchsanstalt fur wasserbau und schiffbau. Berlin, 1936, H. 26, p. 245.

12. Seminara G. Fluvial sedimentary patterns. “Aural Review of Fluid Mechanics». Vol. 42., 2010. Palo Alto (Calif): Annu.Rev.2010, c.43-66.

13. Shuai Wang, Bojie Fu, ShilongPiao, YiheLü, Philippe Ciais, Xiaoming Feng, Yafeng Wang, Reduced sediment transport in the Yellow River due to anthropogenic changes, Nature Geoscience 9, 38-41, 2016.

14. Van Rijn, L.C.,.A simple general expression for longshore transport of sand, gravel and shingle. Coastal Engineering, Vol. 90, 2014. P.23-39

15. S.Eshev, Sh. Latipov, A.Qurbonov, J. Sagdiyev, M. Berdiev ,N. Mamatov. Noneroding speed of water flow of channels running in cohesive soils. Intedration, Partnership. Innovationm in construction science-education (IPICSE 2020). $2020 \mathrm{y}$. 11-14 november. IOP Conf. Series: Materials Science and Engineering 1030 (2021) 012131. IOP Publishing. doi:10.1088/1757-899X/1030/1/012131

16. Joldassov, S.K., Sarbassova, G.A., Bekmuratov, M.M., Zholamanov, N.Z., Yangiev, A.A. New structures of sediment exclusion works. News of the National Academy of Sciences of the Republic of Kazakhstan, Series of Geology and Technical Sciences 6(438). 2019. Pp. 184-189.

17. Kajiura K. A model of the botton boundary layer in water waves. Bulletin of the Earthquake Research Institute, Vol. 46, 1968, 75-123.

18. S.Eshev ,A. Rakhimov1, I. Gayimnazarov, A.Isakov1, B.Shodiev, F.Bobomurodov. Dynamically stable sections of large soil canals taking into account wind waves. Intedration, Partnership. Innovationm in construction science-education (IPICSE 2020). 2020 y. 11-14 november. IOP Conf. Series: Materials Science and Engineering 1030 (2021) 012131. IOP Publishing. doi:10.1088/1757899X/1030/1/012131

19. Yangiev, A., Salyamova, K., Turdikulov, K., Fayziev, X. Dynamics of an earth dam with account for rheological properties of soil under dynamic effect «IOP Conf. Series: Materials Science and Engineering» 869 (2020) 042005 FORM-2020.

20. Choriev, J., Muratov, A., Yangiev, A., Muratov, O., Karshiev, R. Design method for reinforced concrete structure durability with the use of safety coefficient by service life period. IOP Conference Series: Materials Science and Engineering 883(1),012024 2020

21. Eshev S.S. Calculation of deformable large earth canals in conditions of unsteady water flow. T: Voriswillfindit. 2018, P-168.

22. Bazarov D, Vatin N, Bakhtiyor O, Oybek V. Hydrodynamic effects of the flow on the slab of the stand in the presence of cavitation. IOP Conf Ser Mater Sci Eng. 2021;1030:012110.

23. Dilshod Bazarov, Irina Markova BN and OV. Hydraulic aspects of the layout of head structures during water intake from lowland rivers. Ser I O P Conf Sci Mater. 2021;1015:012041. 
24. Dilshod B, Markova I, Sultanov S, Kattakulov F. Dynamics of the hydraulic and alluvial regime of the lower reaches of the Amudarya after the commissioning of the Takhiatash and Tuyamuyun hydrosystems. IOP Conf Ser Mater Sci Eng. 2021;1030:012110.

25. Khidirov S, Jumaboeva G, Ishankulov Z. Hydraulic mode of operation of the Takhiatash hydroelectric complex. 2021;

26. Obidov B, Vokhidov O, Tadjieva D, Saidkhodjaeva D, Kurbanova U, Isakov A. Hydrodynamic effects on the flow elements of the downstream devices in the presence of cavitation. IOP Conf Ser Mater Sci Eng. 2021

27. Uralov B, Rakhmatov N, Khidirov S, Safarov G. Hydraulic modes of damless water intake. 2021;

28. Uralov B, Choriev R, Maksudova L. Substantiation of the influence of the channel shape and the roughness of machine canals on the pressure loss of irrigation pumping stations Substantiation of the influence of the channel shape and the roughness of machine canals on the pressure loss of i. 2021;

29. Matyakubov B, Begmatov I, Raimova I, Teplova G. Factors for the efficient use of water distribution facilities. IOP Conf Ser Mater Sci Eng. 2020 